\title{
Capability of Building Information Modeling Application in Quantity Surveying Practice
}

\author{
Wong Phui Fung ${ }^{1}$, Hafez Salleh ${ }^{2}$ and Faizul Azli Mohd Rahim ${ }^{3}$ \\ ${ }^{1} \mathrm{Ph} . \mathrm{D}$ Candidate, Faculty of Built Environment, University of Malaya, Kuala Lumpur, Malaysia \\ ${ }^{2,3}$ Senior Lecturer, Faculty of Built Environment, University of Malaya, Kuala Lumpur, Malaysia \\ ${ }^{1}$ phuifung @gmail.com
}

\begin{abstract}
Building information modeling (BIM) application has the potential to revolutionize the quantity surveying practice. It appears that quantity surveyors are still lagging behind in BIM application compared to other professionals. Low adoption among quantity surveyors is due to lack of awareness of the potential of BIM application toward their profession. Quantity surveyors are still unsure of the capability of BIM in their practice. It is still generally underexplored how BIM application contributes to quantity surveyors performance improvement. This research attempts to identify the capabilities of BIM application in quantity surveying practice to increase awareness. The scope of this research limited to pre-construction stage. The potential capabilities are found through literatures and verify through interviews with eight quantity surveyors till achieve saturation. The findings indicated that there are 11 potential BIM capabilities that can enhance quantity surveyors' performance and majorities of them are confirmed by the interviewees. These findings provide clear understanding that BIM application has the capabilities to enhance quantity surveyors' performance where traditionally their works are known as time-consuming and error-prone.
\end{abstract}

Keywords: Building Information Modeling (BIM), capability, quantity surveying, construction industry, cost

\section{INTRODUCTION}

Completing a construction project within three important parameters such as time, cost and quality are criteria of success for a project. Azhar et al. (2008) asserts that it is crucial to ensure that the construction cost is within the client's budget because cost is among the major parameter throughout the project life cycle. Quantity surveying is an important discipline that provides cost management services in the construction industry. They are known as cost expert that manage cost for construction client. Quantification, bills of quantities preparation, estimation and pricing of construction projects are major tasks provided by quantity surveyors (QSs). It is noticeable that traditional quantity surveying practice involves tedious and time consuming works. This is due to QSs still using manual practice such as excel spreadsheet and 2D CAD. These methods are less efficient which are susceptible to human errors. As a result, it has reduced the performance of QSs which subsequently affect the project cost outcomes. Besides, clients are becoming dissatisfied with the conventional ways of QSs performing their practice. However, these tedious and time consuming tasks can be eradicated by automating the process through implementing building information modeling (BIM). Perera et al. (2012) pointed out that BIM removes many tedious tasks of traditional quantity surveying, such as measurement, take offs and the production of bills of quantities (BQ), by automating these tasks. It is noteworthy that BIM has enhanced the performance of QSs by taking away the dull of measurement and other tedious tasks. 
Compare to architects and engineers, QSs are lagging behind in BIM implementation (Ho, 2012). $10 \%$ of QSs were using BIM regularly and a further $29 \%$ of QSs have some limited engagement with BIM according to Royal Institute of Chartered Surveyors (RICS) 2011 survey (RICS, 2011). This survey indicated low usage of BIM among QSs is due to the lack of awareness and unsure of its potential usability in their practice. There is limited research on investigations into potential and capabilities of BIM in quantity surveying practice (Mitchell, 2012; Perera et al., 2011). Lack of information regarding BIM application along with uncertain capability from new technology has resulted in reluctance to implement new technology among QSs. QSs who are not familiar with BIM would tend to default back to conventional working methods that impede their job performance. In order to improve this situation, it is crucial to create greater awareness of the potentials and benefits of BIM in surveying practice to increase application (RICS, 2011). Therefore, this research is intended to identify the capabilities of BIM in quantity surveying practice. This study helped to increase awareness of BIM capabilities among quantity surveying profession by promoting the potential usability in quantity surveying practice. Understanding how BIM enhance QSs' performance is important and this assists in the efficient use of BIM in their practice.

\section{BIM APPLICATION IN QUANTITY SURVEYING PRACTICE}

QSs play an essential role in the construction industry. They are responsible for the cost management throughout the entire life span of a project from the feasibility and design stages until building completion. Their services can be divided into two stages, which are pre- and postconstruction stages of the projects. At the pre-construction stage, quantity surveying services include the preparation of preliminary estimates and feasibility studies, cost plans and schedules, bills of quantities preparation, procurement and tendering procedures, and evaluation of tenders (Olatunji et al., 2010). On the other hand, at the post-construction stage, quantity surveying services include providing general contractual advice, assessing interim payments, evaluating variation, preparing finance statements, settling final account, and giving alternative dispute resolution (ADR).

The core services provided by the QSs are measurement and bills of quantities preparation (Olatunji et al., 2010). The process of measuring building quantities of various building elements is defined as quantity taking off (QTO). QTO is a pre-requisite for carrying out several other tasks such as estimating and bills of quantities preparation. However, it is very time-consuming and tedious tasks. Traditionally, the quantities are calculated from paper drawings by hand or using QS software based on 2D CAD drawings. After that, the dimensions are transferred on excel spreadsheet to perform estimating. These conventional working methods are inefficient, time-consuming and prone to error. Hannon (2007) pointed out around 50-80\% of the time spent on quantification by QSs. Mitchell (2012) also highlighted that QSs spend $90 \%$ of their time calculating building quantities. However, BIM technology is a potential solution for the above problems by automating these tedious tasks (Nagalingam et al., 2013; Thurairajah \& Goucher, 2013).

Eastman et al. (2008) defines BIM as "tools, processes and technologies that are performance, its planning, its construction and later its operation (pp. 467)." In their context, BIM is a modeling technology and associated set of processes to produce, insert, share and manage the information in a centralized model to improve designs, constructions, operations and maintenance processes. It is viewed as the development and use of computer generated a multi-dimensional model to simulate the construction process throughout the lifecycle of a construction project. It is a model that stored a wealth of information representing the entire building by incorporating all the designs and information from different design professions. It helps to model real life situation and identify 
potential problems in virtual environment before it comes to actual construction. Clashes and problems can be detected earlier and rectification steps can be taken to minimize the consequences.

BIM has attained attention and gained acceptance in the Architectural, Engineering and Construction (AEC) industry. BIM has the potential to revolutionize the construction industry by changing the traditional working methods of industry profession. Designers have been using BIM widely for visualization of design to improve design outcomes. Contractors have been using BIM for planning and scheduling to monitor construction progress and performance. However, QSs are only recently beginning to be impacted. The introduction of BIM in quantity surveying practices has been brought due to changes in requirements from clients. RICS (2009) articulated the cost planning process has been found to be inconsistent, inaccurate and results in poor cost management services provided by QSs. Meanwhile, building works are getting more complex and clients are becoming dissatisfied with the conventional ways of QSs performing their practice. Hence, it is crucial for QSs to move away from inefficient methods. It is imperative that QSs adopt better and efficient tools to provide time-savings and enhance the quality of the tasks provided. By adopting $\mathrm{BIM}$, it has the potential to remove the technical and labour intensive aspects of the traditional role, as well as to enable improvements in efficiency and performance.

Quantity surveying practice is bound to $5^{\text {th }}$ dimension (5D) of BIM. The 5D BIM is an integration of the 3D BIM model and the construction schedule (4D) with contract pricing (cost) for quantity surveying applications. It stimulates the building performance with respect to its construction cost. BIM automatically generates quantities, take-offs and counts from the model which will reduce the time and costs required to prepare an estimate (Olatunji et al., 2010; Wijayakumar \& Jayasena, 2013). It eliminates the need for tedious manual take-off, human error during estimation and it provides a faster way to analyze data and prepare cost estimates. BIM can offer significant benefits over traditional drawing-based manual taking-off process. When changes happen, it requires manually editing and updating for all drawing views which is tedious and error-prone. The manual process requires a great deal of time and energy to revise the quantities to accommodate the design changes. The QSs would have to constantly check what have been changed, added or omitted. This process is time-consuming and leads to serious consequences if the changes were not detected. BIM has the added advantage over CAD to deal with design change efficiently due to parametric change technology that coordinates changes and maintains consistency when changes happen. A change made in one drawing view will be updated and represented in all other drawing views as well. It allows the QSs to easily identify drawing changes and automatically update the quantities when the design is changed.

Therefore, BIM has changed the way QSs perform their duties and subsequently brings impact on the speed and efficiency of the professional services. It has the potential to influence every aspect of the quantity surveying professional services. By implementing BIM, QSs can improve their performance and productivity as these tedious tasks can be automated by BIM. By cutting down the time spent on quantity take-offs, QSs can spend more valuable time for better and more significant tasks such as advise on design, provide more cost alternatives, estimates and value engineering. The traditional roles of QSs will be assisted by BIM model, so that their responsibilities will shift from bill producers to cost advisors. With BIM's capabilities, it will create new roles and responsibilities for them.

\section{RESEARCH METHODOLOGY}

The research was divided into two phases. Firstly, capabilities of BIM in quantity surveying practice were identified through literature review. Various means were used to gather information 
with regard to capabilities of BIM such as books, academic journals, articles, electronic journal databases and conference proceedings that focused on BIM technology in cost aspect. Apart from that, the reviewed literature also includes white papers and technical reports from vendor (Autodesk), guidelines and reports generated by regulatory and government institutions and newsletters and articles on the practice in the construction industry. RIBA Plan of Work 2013 (Figure 1) is used as template for identifying the tasks provided by QSs in the construction process. This in turn helped to identify BIM capabilities in quantity surveying practice. The scope of this study covered pre-construction stage; hence stage 1 to 4 is applicable. Pre-construction is chosen as many designs and cost decisions are made at this early stage. Poor design and cost advice at the early stage will impact the later construction stage which often caused redesign, change order, rework, and leading to cost and time overrun. Second stage of the research is theory validation by experts' interviews in order to verify the capabilities that have been identified through the review of the literatures. Semi-structured interviews were conducted to obtain details and to gather an indepth understanding of BIM capabilities. All the selected respondents are QSs who have more than 10 years of experience in the construction industry and had adopted BIM in their practice. The interview session reached saturation without new information after 8 interviews. Audio-recorded interviews were transcribed and were analyzed using content analysis. Content analysis is a process designed to reduce massive volumes of data by coding to examine themes and patterns in a particular text to explore the meaning based on interpretation. The first step of content analysis is data preparation by transforming the data into written text that is a complete transcript. Unit of analysis refers to the basic unit of text that is classified before the coding process. The next step is developing a coding scheme by segmenting data into categories. The last step involves making inferences about the categories identified and meanings derived from the data. At the end of the content analysis, the results and discussion are presented.

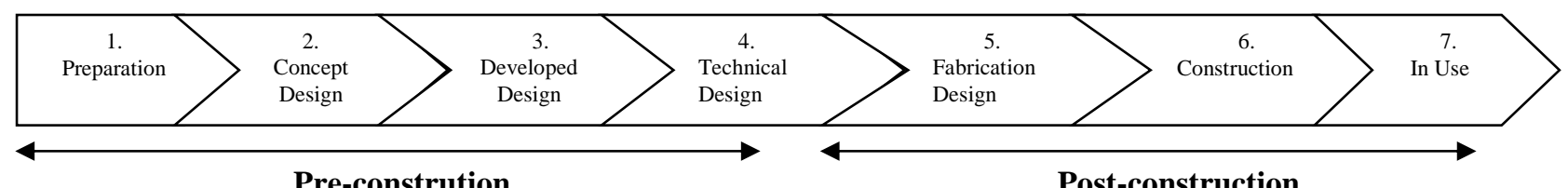

Figure 1: RIBA Plan of Work 2013 (RIBA, 2012)

\section{BIM CAPABILITIES}

BIM capability is defined by Succar et al. (2012) as "the ability to perform a task or deliver a BIM service/product (pp.124)." Hence, the term BIM capability in this study is defined as the ability of BIM to perform tasks in quantity surveying practices in order to enhance their job performances through BIM adoptions. In this context, it is generally taken to mean the strength or competency with regard to BIM that possess in quantity surveying practices.

\section{STAGE 1: PREPARATION STAGE}

Before deciding to start a project, client would like to establish cost limit for the project. At this stage, QSs undertake feasibility studies by preparing cost appraisal to determine the initial building cost. Clients need professional cost advice from QSs to determine and assess the viability and feasibility of undertaking the project. Information available is limited at this stage which consists of simple sketches and other relevant information. DLS (2011) highlighted that information at this level only indicated areas, height, volume, location and orientation which allows estimating done by using cost per unit floor area. BIM allows initial concept estimate to be prepared quickly (Mitchell, 
2012) (C1) with information available. By using BIM, cost geometry can be extracted from the earliest design to generate a basic costing which defines project scope at an elemental level and establishes budget (Exactal Technologies, 2010). Although the cost estimate is simple at this stage but it has the largest impact on the final cost.

\section{STAGE 2: CONCEPT DESIGN}

After establishing the cost range at the feasibility stage, the design team starts to develop the design in more detail at this stage. The task of QSs is to provide a more comprehensive cost estimate based on a better developed design and scope of work. QSs begin to prepare the first structured cost plan; preliminary cost plan which aims to confirm the budget determined at the feasibility stage. The cost plan is presented in a group element format to show cost allocation to major construction elements. It shows the cost distribution to the various group elements that make up project to gain a balanced distribution of cost. BIM will extract as much geometric data as possible depending on the level of data available in the model to generate preliminary cost estimates (Cheung et al., 2012; McCuen, 2008) (C2).

Moreover, BIM is able to speed up cost estimation preparation especially for various design alternatives (C4). This capability enables fast and accurate evaluation of multiple design options (Mitchell, 2012; Perera et al., 2012) for client to choose optimal design that meets his/her requirements. It can be done by conventional working method but the process is tedious, timeconsuming and error prone.

As compared to traditional method, QSs are able to provide preliminary cost estimates of two alternative designs in one day (Fallon \& Mark, 2007) which provides significant time savings (Exactal Technologies, 2010). Hence, it allows a real-time and quick response to design options and encourages the pursuit of more efficient and sustainable designs for better building.

\section{STAGE 3: DEVELOPED DESIGN}

At this stage, design progressively developed as more detailed information become available. QSs conduct further cost studies and estimates to update the cost plans that presented in an elemental cost format, stating the specific construction materials, finishes, specification with elemental unit rates and quantities (Mitchell, 2012) (C3). Conventionally, QSs tend to face difficulty in updating the cost plan as design changed frequently. Cost database in BIM comprises few entries which allow elemental cost plans to be prepared automatically and more detailed through a built-in automation facility in the model estimates (Cheung et al., 2012; Thurairajah \& Goucher, 2013). Thurairajah \& Goucher (2012) stated that detailed cost plans can be generated through linking a "5D Cost Library" to BIM which performs the function of an estimating database. QSs are able to extract element quantities from the model to perform element cost estimation with more detailed breakdown estimates (Cheung et al., 2012). Hence, cost plan can be updated comprehensively and easily as the design develops.

It is noted that drawings, details and specifications from designers are important in this stage for QSs to perform detailed cost estimation. However, information exchanged between various projects stakeholders are executed by sending paper based documents that is highly inefficient and often caused miscommunication. Hence, QSs are facing difficulty to obtain this information timely and accurately from design team to perform their tasks. BIM has the potential to rectify this inefficiency by handling numerous and different information in a single database. Intelligent information management $(\mathrm{C} 11)$ is one of the capabilities of BIM through a repository of information database in 
a model as pointed out by Cheung et al. (2012) and Thurairajah \& Goucher (2013). Besides, one of the objectives at this stage is to integrate detailed design decisions from all designers into a unified scheme. Therefore, design accuracy and consistency among various design discipline is crucial in order to obtain planning approvals. Clash detection (C7) is a key benefit of BIM for QSs to reduce fewer cost estimate revisions as stated by Thurairajah \& Goucher (2013) through overlaying the architectural, structural and MEP designs in model.

Frequently changing in design and scope throughout the design process is a major cause of cost overrun as project cost correlates to the design of building. It can lead to serious impact on the project cost if design changes and revisions are undetected. Dynamic links are generated and created with the model assemblies (architectural, structural, civil, mechanical, engineering and plumbing), elemental areas and rate libraries which establish connection and relationship among these elements (McCuen, 2008; Mitchell, 2012). Autodesk (2011) explained that relationships are automatically built into the model which results in components within the model know how to respond and interact with each other. When changes happen, the quantities of the elements affected are automatically updated and the cost estimates automatically recalculated. Conventionally, QSs will need to track all changes manually which is time consuming to find out what's changed, what's new, what's been omitted or which specification are different from previous design. With this capability, Popov et al. (2010) and Thurairajah \& Goucher (2013) highlighted that cost implication regarding to changes in design can be generated automatically, without the need to recalculate (C6). Cost information is always consistent with the latest design revision without the need of manual remeasurement which is time-consuming and tedious.

\section{STAGE 4: TECHNICAL DESIGN}

There are two major tasks at stage 4 which are cost checking against cost plan and bills of quantities preparation after cost checking. Cost checking and monitoring are important tasks at this stage to ensure every design elements are captured in costing. By doing manually, it requires time and energy of the QSs to check. Besides, items can be easily overlooked or miscalculated in large complex projects which often cause serious impact to project cost. However, visuals on screen checking in the model (C8) for completeness to make sure all items are measured and priced (Exactal Technologies, 2010).

Bills of quantities (BQ) preparation remain as an important service provided by QSs at this stage. It is noteworthy that quantity takeoff is tedious and time consuming task during BQ preparation. It takes up a lot of the QSs' time, focus and attention to count as well as measure each item in the drawing. Automatically quantity takeoff (C10) is one of the BIM capability (Papadopoulos, 2013; Popov et al., 2010) that help to simplify and remove routine and drudgery that come with this task. One-click tools enable take-offs, counts and measurements to be generated directly from the underlying model. The consequences of this capability will mitigate the time wasting and human errors by manual taking off. This inevitably helps to improve QSs' job performance.

One of the problems arises during quantification manually for QSs are the risk of using obsolete drawings. More often, change in drawing plan is not updated in the section or schedules which caused design discrepancies. Changes are frequently happen and it requires QSs' attention to capture all the changes in the drawing. By using BIM, changes will be automatically depicted in the model and will also be propagated throughout all drawing views (Chang \& Shih, 2013) (C5). Hence, drawing revisions automatically updated and identified (Exactal Technologies, 2010) into a computerized model rather than architectural drawings (Mihindu \& Arayici, 2008). Hence, latest 
revision to the design could be captured automatically to reflect current design drawing revisions. It reduces the risk of QSs to use obsolete drawings for quantification and estimation.

On the other hand, the largest problem in the building project is the misinterpretation of design drawings. Witicovski \& Scheer (2012) highlighted the largest problem in estimating is the incorrect visualization and interpretation of the project information. If it is not fully visualized and understood, it can be interpreted wrongly in the contract documents and may consequently create conflicts during construction. BIM visualization (C9) has been recognized as an effective tool in better understanding a project's design especially complex relationships and complex systems (Thurairajah \& Goucher, 2012). Papadopoulos (2013) highlighted that BIM facilitates QSs' understanding of the project design by improving visualization. This capability will enhance QSs' understanding on the design especially complex designs and structures and subsequently enables QSs provide accurate estimation.

\section{SUMMARY OF BIM CAPABILITIES IN QUANTITY SURVEYING PRACTICE}

In sum, eleven capabilities of BIM were found in quantity surveying practice as illustrated in Table 1. These eleven capabilities identified through literature reviews are verified with QSs through interviews.

Table 1: BIM capabilities in quantity surveying practice

\begin{tabular}{ll}
\hline Tag & Capability \\
\hline C1 & Cost appraisal can be prepared quickly at feasibility stage. \\
\hline C2 & Preliminary cost plan can be prepared by extracting quantities from model. \\
\hline C3 & Easily update cost plan more details as design developed. \\
\hline C4 & Easily generate accurate cost estimates for various design alternatives \\
\hline C5 & Design changes reflected consistently in all drawing views \\
\hline C6 & $\begin{array}{l}\text { Cost implication of design changes can be generated easily without manually re- } \\
\text { measurement }\end{array}$ \\
\hline C7 & Clash detection reduces design errors and cost estimates revisions. \\
\hline C8 & Cost checking performs quickly to ensure all items are captured \\
\hline C9 & Improve visualization for better understanding of design. \\
\hline C10 & Automatically quantification for BQ preparation. \\
\hline C11 & $\begin{array}{l}\text { Intelligent information management allows data to be stored in a central } \\
\text { coordinated model. }\end{array}$ \\
\hline
\end{tabular}

\section{RESEARCH FINDINGS AND DISCUSSION}

The content analysis outlined that five interviewees confirmed all eleven BIM capabilities identified from the literature. However, C5 was not confirmed by Interviewee A, C7 was not confirmed by interviewee $\mathrm{C}$ and $\mathrm{C} 11$ was not confirmed by interviewee $\mathrm{H}$, through the qualitative analysis, although they were identified in the literature. In sum, eight capabilities of BIM were viewed by all interviewees as the capability of BIM in quantity surveying practice. It is noted that capability C5, C7 and C11 were disagreed by one interviewee but confirmed by the other seven interviewees. Majority of the interviewees confirmed capability C5, C7 and C11. It can be concluded that all capabilities are confirmed by interviewees as capabilities of BIM in quantity surveying practice. 


\section{COST APPRAISAL CAN BE PREPARED QUICKLY AT FEASIBILITY STAGE (C1)}

C1 was viewed as capability of BIM in quantity surveying practice by all interviewees. With level of detail (LOD) 100, quantities can be extracted faster from the model which eases the preparation of cost appraisal. Client can obtain cost appraisal quickly at the beginning stage which facilitate the decision making process. Majority of the interviewees said that:

"...quantity can be extracted very quickly from the model."

\section{PRELIMINARY COST PLAN CAN BE PREPARED BY EXTRACTING QUANTITIES FROM MODEL (C2)}

$\mathrm{C} 2$ was identified by all interviewees as capabilities of BIM in quantity surveying practice. $\mathrm{C} 1$ is similar to $\mathrm{C} 2$ with different LOD for quantities extraction from model. By showing preliminary cost plan quickly and accurately, client will obtain a good understanding of the cost breakdown. One of the interviewees mentioned that:

“....preliminary cost plan can be done quickly with different LOD in the model."

\section{EASILY UPDATE COST PLAN MORE DETAILS AS DESIGN DEVELOPED (C3)}

C3 was regarded as a capability of BIM in quantity surveying practice as perceived by all interviewees. Due to design variation and change of client's requirements, cost plan tends to change frequently. As a result, QSs take times to update the cost plan frequently whenever design changes. However, with this BIM capabilities, cost plan can be updated easily and smoothly whenever design changes. It allows the work to be done quicker and accurately than QS can do manually. For instance, an interviewee stated that:

"....it takes few weeks to do it conventionally, but it can be done less than an hour with BIM."

\section{EASILY GENERATE ACCURATE COST ESTIMATES FOR VARIOUS DESIGN ALTERNATIVES (C4)}

All interviewees acknowledged C4 as BIM capabilities in quantity surveying practice as more cost alternatives can be produced at shorter times for different design options. Majority of the interviewees highlighted that it can be done by traditional way; however it is time-consuming and prone to errors. One of the interviewee shared his experience of using BIM for a project and stated: "...BIM allows us to prepare estimate quickly for few façade designs."

With this capability, QSs can provide few cost estimates for different design quickly for clients to choose optimal design. This capability allows QSs provide client accurate cost advice which subsequently increases clients' satisfaction. Few interviewees commented that:

“...Clients request for more alternatives but QSs are facing difficulty to produce it by using conventional method. However by using BIM, QSs are able to perform what-if analysis with more cost alternatives for clients to make better informed decisions."

\section{DESIGN CHANGES REFLECTED CONSISTENTLY IN ALL DRAWING VIEWS (C5)}

C5 was recognized as capability of BIM by majority of the interviewees except interviewee A. One of the problems occurs when design change is drawing coordination. Drawings plan, sections, elevations, schedules and other related documents need to be updated manually to reflect the latest design. BIM contains parametric change technology that has the ability to coordinates changes and 
maintains consistency every time changes happen. Design change is immediately reflected and update everywhere without intervention from the project users. With this capability, latest iteration of the design is ensured. Most importantly, QSs can avoid using obsolete drawings for quantification and estimating. An example was quoted from one of the interviewees:

"...changes frequently happen in a project. BIM is the best tool to rectify the impact of the changes. It allows coordination to be done quickly if changes occur."

Interviewee A argued that this capability doesn't happen automatically as every project parties are using different types of files format which hinder changes reflected consistently in all drawing views. Nevertheless, the other seven interviewees agreed that this capability enables changes to be made promptly and all views of the model are changed iteratively.

\section{COST IMPLICATION OF DESIGN CHANGES CAN BE GENERATED EASILY WITHOUT MANUALLY RE-MEASUREMENT (C6)}

C6 was viewed by all interviewees as capability of BIM in quantity surveying practice. As mentioned earlier, design changes frequently happen in construction project. It has influenced the cost of the project. QSs have to prepare the cost implication within shorter time for clients. BIM has the capability for cost implication to be generated faster and accurately without the need to remeasure. Cost differences can be known easily which allow client to see how the changes affect the total cost of a building. An interviewee further explained that:

"... BIM identified changes and generate cost implication by a press of button. It's fast and accurate."

\section{CLASH DETECTION REDUCES DESIGN ERRORS AND COST ESTIMATES REVISIONS (C7)}

C7 was identified as capability of BIM by majority of the interviewees except interviewee C. Design errors can be detected immediately which subsequently reduce cost estimate preparation by QSs. Interviewee $\mathrm{C}$ argued that the quality of the design from different consultants make it difficult to detect clashes. Despite this, most of the interviewees perceived this capability allows building performance to be simulated digitally so that design conflicts can be resolved upfront to avoid rework. Majority of the interviewees mentioned that:

"...by detecting errors at the early stage, it would reduce mistake at the later stage which reduce cost estimate revision and variation orders during construction stage. It saved QSs' work."

\section{COST CHECKING PERFORMS QUICKLY TO ENSURE ALL ITEMS ARE CAPTURED (C8)}

C8 was highlighted by all interviewees as one of the BIM capability in quantity surveying practice. QSs have to perform cost checking to ensure design elements are included in the costing. However, due to complex design or involve too many design elements, QSs tend to spend more time to perform cost checking. It also increases the risk of missed out items. Interviewees highlighted with this capability, QSs can visual on screen to perform cost checking. It reduces the risk of missed out items which has serious impacts on the costing. One of the interviewees shared his experience of using BIM by stating:

"...elements can be shaded by colours in the model to ensure it captured in the costing. So, it avoids missed out items and reduce risk of making errors." 


\section{IMPROVE VISUALIZATION FOR BETTER UNDERSTANDING OF DESIGN (C9)}

C9 was essentially viewed to be important in quantity surveying as BIM capability by all interviewees. QSs tend to use longer time to study and understand the design especially complex design and irregular shapes. It requires QSs' imagination and interpretation. It is noted that correct interpretation is correlated with accurate costing. 3D visualization is the utmost capability of BIM to enhance QSs' understanding on the design and subsequently they can provide accurate costing for the design. All of the interviewees highlighted that:

"... QSs can visual for better understanding. They can walk through the model to have better imagination"

\section{AUTOMATICALLY QUANTIFICATION FOR BQ PREPARATION (C10)}

C10 was regarded by all interviews as BIM capability. Quantification is known as the most timeconsuming task performed by QSs. Majority of the interviewees highlighted that it takes out $90 \%$ of QS's times. This capability enables quantity to be captured automatically. Hence, it reduces the tediousness of performing quantification and simplifies the cumbersome tasks. Moreover, QSs can spend time on performing estimating rather than quantification which will improve project performance and client satisfaction. Majority of the interviewees stated that:

"... BIM automatically generated the quantities by few clicks of button."

\section{INTELLIGENT INFORMATION MANAGEMENT ALLOWS DATA TO BE STORED IN A CENTRAL COORDINATED MODEL (C11)}

C11 was viewed as BIM capability by all interviewees except interviewee $\mathrm{H}$. In order to perform tasks, QSs have to request information manually from consultants. It often takes times and the information may be obsolete. BIM model is a rich repository that contains information from different multi-disciplinary. BIM uses a centralized model to coordinate all drawings plans, sections, elevations and other related documents which result in better coordinated construction documents that reduce errors and omissions. This approach gives QSs easy access to information. One of the interviewees pointed out:

"...BIM has the capability to keep all information in one single model which allows project parties refer to the correct information source."

Nonetheless, this capability is difficult to achieve at the moment as pointed out by interviewee H. It requires efforts from multidisciplinary players to insert all information in the model which particularly is not practice currently in the construction industry.

\section{SUMMARY OF DISCUSSION WITH INTERVIEWEES}

All interviewees accentuated that BIM has the capabilities to improve the performance of QSs. Traditional QSs tasks are time consuming and prone to error. However, interviewees pointed out that time issues can be addressed and errors can be eradicated by using BIM in quantity surveying practice. The eleven BIM capabilities found through literatures and discussed during interviews are informative to increase the understanding of QSs regarding the capabilities of BIM in their practice. It helps to promote the potential of BIM in quantity surveying practice as it can ease their job. By knowing these BIM capabilities, QSs can adopt BIM to the full potential in their practice to increase job performances. In addition, the interviewees highlighted that there are still many issues and challenges in BIM adoption among QSs. Majority of them urged that there is a need to change the 
mindset and attitude among QSs toward BIM adoption. Positive mindset and attitude is crucial as BIM workflow is new and different approach as compare to traditional workflow. All interviewees pointed out QSs are reluctant to adopt BIM in their practice due to lack of understanding in the capabilities of BIM in their practice. Hence there is a need to increase the understanding among QSs by promoting BIM capabilities. BIM is an innovative tool for enhancing job performance rather than roles replacements. It takes away the tediousness of tasks such as quantities measurement and allows QSs to perform more value-added services for clients. It is important to note that industry requirements are changing and requesting different services from professional QSs. Hence, BIM application is an opportunity for QSs to diversify their roles and responsibilities.

\section{CONCLUSION}

Conventional working methods performed by QSs are time-consuming, inefficient and prone to errors. Majority of the quantity surveying organizations are still heavily rely on traditional means of working method such as manual taking-off and exchange of paper based documents. It is found that BIM has the capability to enhance the performance of QSs. Eleven capabilities of BIM in quantity surveying are identified through literature review. Qualitative interviews concluded that majority of the capabilities are confirmed by the interviewees. This study helped to increase awareness of BIM capabilities among quantity surveying profession by promoting the eleven capabilities of BIM in quantity surveying practice. Understanding how BIM enhance QSs' performance is important and this assists in the efficient use of BIM in their practice. By identifying eleven BIM capabilities, it is recommended that QSs devote more effort towards BIM application in order to improve their job performance and moving away from traditional inefficient working methods. Increase awareness of BIM capabilities would give significant benefits to the QSs and consequently to the construction industry.

During the interviews, all interviewees stressed that BIM has the capabilities to improve the performance of QSs and subsequently enhance the project performance. Majority of them urged for BIM application in quantity surveying practice. However, there are many issues and challenges of BIM application in quantity surveying practice. One of the problems is lack of awareness and resistance to change. Majority of the QSs are not aware of the capabilities of BIM in their practice. Hence, this research is conducted to identify the BIM capabilities and promote BIM capabilities to QSs. BIM is an innovative tool for enhancing job performance rather than roles replacements. It takes away the tediousness of quantities measurement and allows QSs to perform more value-added services for clients. The traditional roles of QSs will be assisted by BIM model, so that their responsibilities will shift from bill producers to cost advisors. It is important to note that industry requirements are changing and requesting different services from professional QSs. Hence, BIM application is an opportunity for QSs to diversify their roles and responsibilities and increase job efficiency. This research will alert the government and professional bodies to develop suitable guidelines and strategies for BIM application among QSs. The relevant parties have to take note on the challenges and issues hindering the application among QSs by identifying suitable strategies to facilitate adoption. It is recommended that future research should focus on the challenges and obstacles of BIM application in quantity surveying practice.

\section{REFERENCES}

Autodesk White Paper. (2011). Realizing the Benefits of BIM. Retrieved from http://images.autodesk.com/adsk/ files/2011_realizing_bim_final.pdf 
Azhar, N., Rizwan U. Farooqui \& Ahmed, S.M. (2008). Cost overrun factors in construction industry of Pakistan. Advancing and integrating construction education, Reseach \& Practice, pp. 499-508.

Chang, Y.F. \& Shih, S.G. (2013). BIM-based computer-aided architectural design, Computer-Aided Design \& Applications, 10 (1) pp. 97-109.

Cheung, F. K. T., Rihan, J., Tah, J., Duce, D., \& Kurul, E. (2012). Early stage multi-level cost estimation for schematic BIM models. Automation in Construction, 27, pp. 67-77.

Davis Langdon \& Seah (DLS). (2011). Quarterly Construction Cost Review - Fourth Quarter.

Eastman, C., Teicholz, P., Sacks, R., \& Liston, K. (2008). BIM Handbook: A guide to building information modelling for owner, managers, designers, engineers, and contractors, New Jersey: John Wiley and Sons, Inc.

Exactal Technologies. (2010). The 21st century estimating solution for BIM. Retrieved from http://www.exactal.com/products/costX

Fallon, K. K., \& Mark, E. P. (2007). General buildings information handover guide: Principles, methodology and case studies (NISTIR 7417). Retrieved from http://www.fiatech.org/pdfs/articles/NISTIR7417.pdf

Hannon, J. J. (2007). Estimators' functional role change with BIM, AACE International Transactions. 1-8.

Ho, T. (2012). Divisional news \& activities. Quantity surveying division: Chairman's message. Retrieved from http://www.hkis.org.hk/en/st/ST2012/201203/2012st03_5f_qsd.pdf

McCuen, T. L. (2008). Scheduling, estimating, and BIM: A profitable combination. AACE International Transactions, pp BIM11-19.

Mihindu, S., \& Arayici, Y. (2008). Digital construction through BIM systems will drive the reengineering of construction business practices. Paper presented at the Visualisation, International Conference.

Mitchell, D. (2012). 5D BIM: Creating cost certainty and better buildings. Paper presented at the 2012 RICS Cobra, Las Vegas, Nevada USA.

Nagalingam, G., Jayasena, H. S., \& Ranadewa, K. (2013). Building information modelling and future quantity surveyor's practice in Sri Lankan construction industry. paper presented at The Second World Construction Symposium 2013: Socio-Economic Sustainability in Construction, 14-15 June 2013, Colombo, Sri Lanka.

Olatunji, O. A., Sher, W., \& Gu, N. (2010). Building information modeling and quantity surveying practice. Emirates Journal for Engineering Research, 15 (1), 67-70.

Papadopoulos, N. (2013). ASPE standard estimating practice, 8th Edition, building information modelling section Retrieved from http://www.eosgroup.com/product_pdfs/BIM_White_ Paper_2.pdf

Perera, S., Udeaja, C., Zhou, L., Rodrigo, A., \& Park, R. (2012). Mapping the e-business profile and trends in cost management in the UK construction industry. Retrieved from http://innovationinaec2012.pcc.usp.br/PROCEEDINGS/88\%20MAPPING\%20THE\% 20EBUSINESS\%20PROFILE\%20AND\%20TRENDS\%20IN\%20COST\%20MANAGEME NT\%20IN\%20THE\%20UK\%20CONSTRUCTION\%20INDUSTRY.pdf

Popov, V., Juocevicius, V., Migilinskas, D., Ustinovichius, L., \& Mikalauskas, S. (2010). The use of a virtual building design and construction model for developing an effective project concept in 5D environment. Automation in Construction, 19 (3) pp. 357-367.

RIBA. (2012). RIBA plan of work 2013: Consultation document. Retrieved from http://www.architecture.com/files/ribaprofessionalservices/practice/frontlineletters/ribaplano fwork2013consultationdocument.pdf

RICS. (2009). RICS new rules of measurement: Order of cost estimating and elemental cost planning (1st ed.). London: Royal Institute of Chartered Surveyors. 
RICS. (2011) Building information modelling survey report, 2011. Retrieved from http://www.bcis.co.uk/downloads/RICS_2011_BIM_Survey_Report.pdf

Succar, B., Sher, W., \& Williams, A. (2012). Measuring BIM performance: Five metrics. Architectural Engineering and Design Management, 8 (2) pp. 120-142.

Thurairajah, N., \& Goucher, D. (2013). Advantages and challenges of using BIM: A cost consultant's perspective. Paper presented at the 49th ASC Annual International Conference Proceedings.

Thurairajah, N., \& Goucher, D. (2012). Usability and impact of BIM on early estimation practices: A cost consultant's perspective. Paper presented at the International Congress on Construction Management Research, Montreal.

Wijayakumar, M. \& Jayasena, H. S. (2013), “Automation of BIM quantity take-off to suit QS's requirements," Paper presented at The Second World Construction Symposium 2013: Social Economic Sustainability in Construction. 14-15 June, Colombo, Sri Lanka.

Witicovski, L. C., \& Scheer, S. (2012). Some improvements for BIM based cost estimation. Retrieved from http://innovationinaec2012.pcc.usp.br/PROCEEDINGS/70\%20SOME \%20IMPROVEMENTS\%20FOR\%20BIM\%20BASED\%20COST\%20ESTIMATION.pdf 